\title{
Effect of Co-Articulation on One Third Octave Spectral Amplitudes of Vowel /I/
}

\author{
A Navya, M Pushpavathi, Nikitha K \\ AIISH, India
}

Submission: November 07, 2017; Published: November 27, 2017

*Corresponding author: A Navya, AIISH, Mysore, 48, First Floor, Maruthi temple road, T.K. Layout, Kuvempunagar, Mysore, India, Tel: 9036377964; Email: navyaaslp@gmail.com

Abstract

Hypernasality is one of the core speech characteristics observed in the speech of children with repaired cleft lip and palate. One-third-octave analysis has been considered as a potential tool to measure acoustic correlates of hypernasality in the speech of individuals with RCLP. However, the acoustic characteristics of speech are influenced by the contextual effects. Hence, the present study aimed to find out the difference in one third octave spectral amplitudes of vowel /i/ across various contexts in children with RCLP and typically developing children. A total of 24 participants (12-RCLP, 12-TDC) in the age range of 4-12 years were considered for the study. The speech sample recorded included repetition of isolated vowel /i/ and vowel /i/ in the phonetic context of /pit/ and /tip/. The one third octave spectral amplitudes were measured for all the stimuli and compared across the groups using MATLAB. The results indicated that energy concentration over one third octave spectrum was more in RCLP group for stimulus /i/, /pit/, \&/tip/ as compared to control group. The spectral energy at low frequencies $(97 \mathrm{~Hz}, 125 \mathrm{~Hz}$ and 157.5 $\mathrm{Hz}$ ) of the isolated vowel /i/ demonstrated a significant increase in spectral energy in RCLP than the control group. The study also reported higher spectral amplitudes for vowel /i/ in the context of /pit/ and /tip/ across frequencies as compared to the spectral amplitudes of isolated vowel /I/ across the groups. The differences were attributed to the influence of phonetic context on the spectral amplitude of vowel /i/.

\section{Introduction}

Hypernasality is a perceptual quality associated with excessive nasal resonance because of velopharyngeal incompetence [1]. It is one of the major speech deviances exhibited by individuals with cleft lip and palate (CLP). The evaluation of hypernasal speech of children with repaired cleft lip and palate (RCLP) can be carried out using various methods. The acoustic analysis is one of the objective techniques which intend to directly study the speech production mechanism. Nasalization with its characteristic acoustic features affects the acoustic analysis of a speech signal. The speech signal gets influenced by dampening effect and by anti formants which will have a major impact on acoustic signal [1]. This technique is advantageous as it is non-invasive, cost effective, and since it can be applied to speakers with various age, gender and speech impairments with different etiologies [2].

Kent, Liss and Philips [3] and Chen [4] described the acoustic correlates of nasalized vowels in spectrograms. They reported an increase in formant bandwidths, the overall reduction in the amplitude of the vowel. They also noticed the low energy of the upper formants as a result of the presence of ant formants. Among the acoustic measures, one third octave spectral analysis is one of the spectral measures which is considered as a potential tool to measure acoustic correlates of hypernasality in the speech of individuals with RCLP. One third octave interval was chosen as it can be judged well against the critical bandwidth of ear's analyzing mechanism [5]. The power spectrum extracted from digitized samples was analyzed at every one third octave band to calculate the mean power level of each band. These levels were then normalized relative to the amplitude of the band that contained the fundamental frequency [5]. This tool has been proved to quantify the degree of hypernasality [6]. The recent studies focusing on spectral features of hypernasal speech have been investigated hypernasality in the speech of children and young adults with cleft palate and cleft lip using one third octave analysis and in adults following maxillectomy.

Kataoka et al., [7] aimed at correlating the once third octave spectral evaluation with the perceived nasality in children with cleft palate and controls. When the two groups were compared, it was shown that the spectrum of hypernasality group was marked by increased spectral amplitudes between F1 and F2 and a reduction in spectral amplitudes around F2 region which differentiated the two groups. They obtained a highly significant correlation ( $\mathrm{r}=0.84)$ between perceptual ratings and amplitudes of one third octave spectral bands $(1 \mathrm{k}, 1.6 \mathrm{k}, \& 2.5 \mathrm{kHz})$ using multiple regression analysis. In the same line of thought, Navya [7] measured one third octave band spectrum in vowels /a/ and /i/ and looked for its sensitivity and specificity in differentiating hypernasality group from the control group. The results indicated increase in amplitudes was observed for frequencies below $1000 \mathrm{~Hz}$ which demonstrated 
a significant difference between the two groups. Another major finding of the study was that the high sensitivity and specificity was found for the frequency region between $998 \mathrm{~Hz}$ and $2663 \mathrm{~Hz}$ which shown to be better differentiating the two groups using $1 / 3$ rd octave spectra analysis. However, there are variations seen in the spectral characteristics with respect to speakers and phonetic contexts $[8,9]$.

The majority of the studies incorporated vowels as the stimulus for carrying out an acoustic analysis of hypernasal speech. Among vowels, vowel /i/ was chosen as the optimal stimulus to determine nasality owing to the fact that high vowels are produced with greater velar height and it demands relatively less nasal coupling for it to be perceived as nasal, compared with low vowels [10-12]. However, it is observed that the acoustic property of a vowel gets influenced by coarticulatory effects. Coarticulation is regarded as a process whereby the properties of a segment are altered due to the influences exerted on it by neighbouring segments. Several studies have documented the variation in the acoustic features of vowels that were seen as a function of consonantal context. Lindblom [13] had observed the effect of three consonants (/bVb/, /dVd/) on eight Swedish vowels and compared the production of the same vowels in isolation. The results revealed that in the context of consonants, the formant frequency of a given vowel fails to achieve its target values than in a neutral context. Therefore, it was concluded that the vowel varied as a function of consonantal context and this effect was termed it as a formant undershoot. Hence, the present study aimed to evaluate the difference in one third octave spectral amplitudes of vowel /i/ across various contexts in children with RCLP and typically developing children.

Aim of the study: To evaluate one third octave spectral amplitudes of isolated vowel /i/ and also in the context of /pit/ and /tip/ in children with RCLP and typically developing children.

\section{Method}

\section{Participants}

The present study considered 24 children in the age range of six to ten years. Among 24 children, 12 children with repaired cleft lip and palate having no associated anomalies and 12 age and gender matched typically developing children served as controls. The control subjects had no history of ear, nose, and throat infections and all the participants in both the groups were screened for hearing loss prior to the inclusion. The informed consent was provided to the parents/caretakers of the participants.

\section{Results}

\section{Descriptive and non- parametric statistical test results}

Table 1: Mean and SD of one-third octave spectral amplitudes across frequencies, stimuli, and groups.

\begin{tabular}{|c|c|c|c|c|c|c|c|c|c|c|c|c|}
\hline \multirow{3}{*}{$\begin{array}{c}\text { Frequencies } \\
\text { (Hz) }\end{array}$} & \multicolumn{6}{|c|}{ RCLP group } & \multicolumn{6}{|c|}{ TDC GROUP } \\
\hline & \multicolumn{2}{|c|}{ /i/ } & \multicolumn{2}{|c|}{ /pit/ } & \multicolumn{2}{|c|}{ /tip/ } & \multicolumn{2}{|c|}{ /i/ } & \multicolumn{2}{|c|}{ /PIT/ } & \multicolumn{2}{|c|}{ /TIP/ } \\
\hline & $\begin{array}{l}\text { Mean } \\
\text { (dB) }\end{array}$ & $\begin{array}{c}\text { SD } \\
\text { (dB) }\end{array}$ & $\begin{array}{c}\text { Mean } \\
\text { (dB) }\end{array}$ & $\begin{array}{c}\text { SD } \\
\text { (dB) }\end{array}$ & $\begin{array}{c}\text { SD } \\
\text { (dB) }\end{array}$ & SD & $\begin{array}{l}\text { Mean } \\
\text { (dB) }\end{array}$ & SD & Mean & SD & Mean & SD \\
\hline 12.4 & 8.39 & 3.54 & 12.12 & 4.80 & 14.73 & 5.01 & 6.40 & 1.04 & 14.02 & 4.22 & 12.50 & 5.37 \\
\hline
\end{tabular}


Global Journal of Otolaryngology

\begin{tabular}{|c|c|c|c|c|c|c|c|c|c|c|c|c|}
\hline 15.6 & 9.91 & 3.23 & 14.13 & 4.07 & 15.64 & 4.68 & 8.40 & 1.04 & 15.42 & 3.64 & 14.40 & 4.99 \\
\hline 19.7 & 11.00 & 2.75 & 15.17 & 3.63 & 15.61 & 5.04 & 9.61 & 0.97 & 16.04 & 3.68 & 16.08 & 5.02 \\
\hline 24.8 & 19.70 & 3.79 & 21.73 & 3.77 & 22.55 & 3.84 & 18.25 & 0.17 & 21.34 & 1.68 & 21.13 & 2.21 \\
\hline 31.3 & 21.46 & 1.34 & 23.15 & 1.61 & 23.96 & 2.07 & 20.94 & 0.26 & 23.35 & 1.42 & 23.20 & 2.13 \\
\hline 39.4 & 10.74 & 5.49 & 17.10 & 5.39 & 17.58 & 7.24 & 8.88 & 2.51 & 18.41 & 5.23 & 17.94 & 5.79 \\
\hline 49.6 & 16.42 & 5.79 & 20.39 & 5.77 & 22.25 & 6.09 & 14.33 & 1.01 & 21.11 & 3.65 & 19.74 & 4.55 \\
\hline 62.5 & 19.42 & 4.06 & 22.60 & 4.23 & 23.87 & 4.60 & 17.75 & 0.49 & 22.91 & 2.89 & 22.49 & 3.81 \\
\hline 78.7 & 15.93 & 6.07 & 21.44 & 5.66 & 23.06 & 6.33 & 12.60 & 1.88 & 22.30 & 4.45 & 21.15 & 5.47 \\
\hline 99.2 & 17.04 & 6.30 & 23.45 & 5.70 & 24.22 & 6.59 & 12.99 & 2.28 & 23.70 & 4.61 & 22.40 & 5.54 \\
\hline 125 & 18.97 & 7.12 & 24.60 & 6.13 & 25.90 & 7.02 & 14.35 & 2.37 & 25.17 & 4.56 & 24.09 & 5.37 \\
\hline 157.5 & 21.51 & 5.80 & 26.50 & 5.55 & 28.15 & 6.19 & 17.05 & 2.42 & 27.40 & 4.55 & 26.69 & 4.90 \\
\hline 198.4 & 26.40 & 5.39 & 29.55 & 5.59 & 30.94 & 6.01 & 23.02 & 5.84 & 30.49 & 4.67 & 30.73 & 4.18 \\
\hline 250 & 47.38 & 10.89 & 36.20 & 7.55 & 36.75 & 6.30 & 40.56 & 10.24 & 37.74 & 5.44 & 39.35 & 6.14 \\
\hline 315 & 44 & 11.04 & 46.95 & 7.97 & 48.29 & 7.28 & 43.51 & 11.17 & 49.34 & 5.98 & 46.85 & 6.41 \\
\hline
\end{tabular}

Note: RCLP: Repaired Cleft Lip and Palate; TDC: Typically developing children; SD: Standard Deviation

The descriptive statistical analysis of the data was performed. The table 1 and figure 1 depicts the mean and standard deviation for isolated vowel /i/, /i / in the context of / pit/ and /tip/ across the frequencies and groups. Figure 1 describes the variations in energy concentration with respect to frequencies across RCLP and normal groups for different stimuli. In general, it can be depicted that as the frequencies increased, there was a rise in amplitudes for both the groups across the stimuli. It is observed that frequencies from $12.4 \mathrm{~Hz}$ to $31.3 \mathrm{~Hz}$ showed an overall increase in the amplitudes across all the groups for all the stimuli. However, at $39.4 \mathrm{~Hz}$, there is a sudden drop in amplitudes for both the groups and also a gradual rise of amplitudes was observed from $49.6 \mathrm{~Hz}$ to $198.4 \mathrm{~Hz}$. Later, again there is a significant increase in energy concentration for frequencies $250 \mathrm{~Hz}$ and $315 \mathrm{~Hz}$.

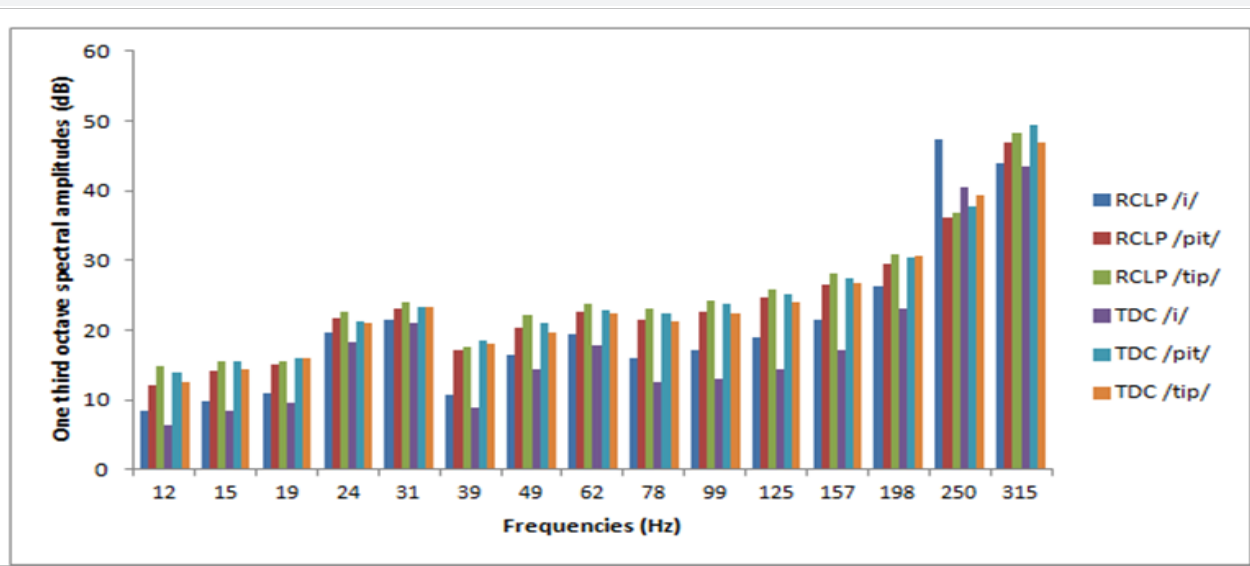

Figure 1: The amplitudes of one third octave frequencies $(12 \mathrm{~Hz}$ to $315 \mathrm{~Hz})$ across stimuli and groups.

One more major finding of the study is that, across frequencies, for both the groups of RCLP and TDC, mean amplitude values of /pit/ and /tip/ were higher when compared to the isolated /i/ stimulus which explains the effect phonetic context on spectral features of /i/. From figure 1, it was apparent that the relative differences in spectral amplitudes across the groups were higher for the isolated vowel /i/ than vowel /i/ in the context of /pit/ and / tip/. The isolated vowel /i/ exhibited increased spectral amplitudes in the RCLP group compared to the normals. The one-third-octave spectral amplitudes between the two groups for the vowel /i/ in / pit/ and /tip/ context were overlapping, which failed to stand as a differentiating factor.
The table 2 and figure 2 represents the amplitudes of frequencies from $396 \mathrm{~Hz}$ to $8 \mathrm{KHz}$ for the stimulus /i/, / pit/ and /tip/ across the two groups. From figure 2, it can be noticed that there is a gradual reduction in the spectral amplitudes from $793 \mathrm{~Hz}$ to $2519 \mathrm{~Hz}$ across the groups. Then for $3174 \mathrm{~Hz}$ and $4000 \mathrm{~Hz}$, there is a rise in the spectral amplitudes followed by gradual reduction while reaching to $8000 \mathrm{~Hz}$. The frequencies $1000 \mathrm{~Hz}, 1259.9 \mathrm{~Hz}, 1587.4 \mathrm{~Hz}$ and $2000 \mathrm{~Hz}$ demonstrated a significant increase in amplitudes of the isolated vowel /i/ across the groups. For vowel /i/ in the context of /pit/ and /tip/, the spectral energy in the frequency bands between $630 \mathrm{~Hz}$ to $2519 \mathrm{~Hz}$ demonstrated higher amplitudes for RCLP group than TDC. To check the normality, Shapiro-Wilk test of 


\section{Global Journal of Otolaryngology}

normality was applied. Review of the S-W test for normality of one third- octave spectral amplitudes for RCLP and TDC group indicated the skewed distribution of the data. Followed by the normality test, the data was subjected to non-parametric statistical test i.e.,
Mann-Whitney U test. The Mann-Whitney U test was conducted to evaluate the null hypothesis that there is no change in participant's amplitude scores when measured across the stimuli and between the groups (Table 3)

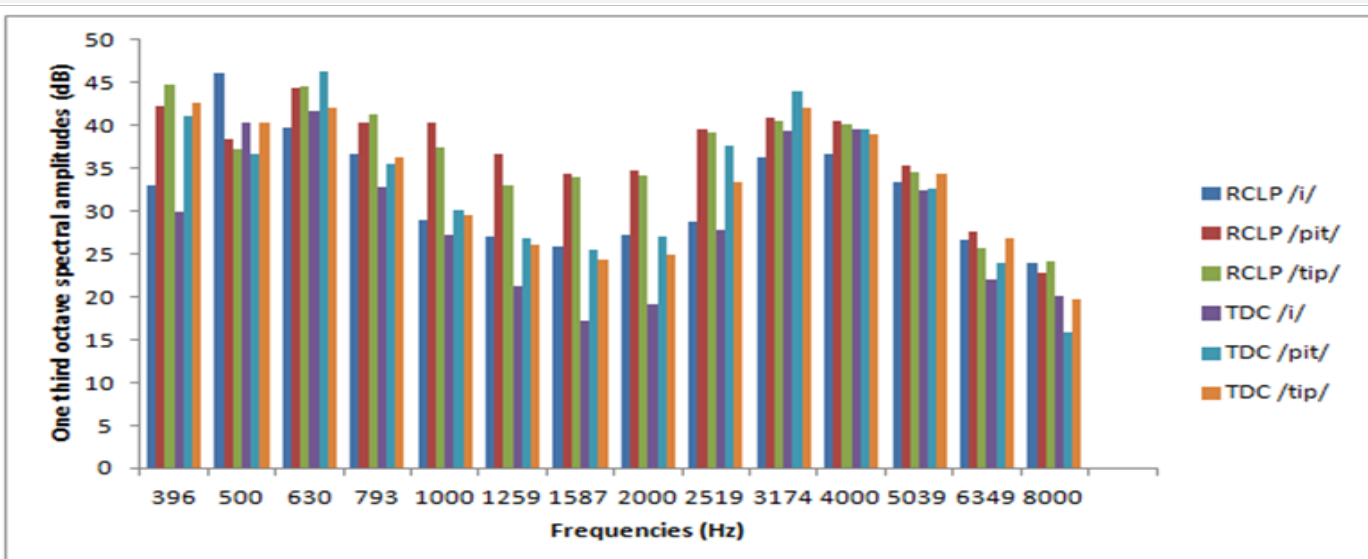

Figure 2: The amplitudes of one third octave frequencies $(396 \mathrm{~Hz}$ to $8000 \mathrm{~Hz}$ ) across stimuli and groups.

Table 2: Mean and SD of amplitudes at various frequencies across the stimuli in RCLP and normal group

\begin{tabular}{|c|c|c|c|c|c|c|c|c|c|c|c|c|}
\hline \multirow{3}{*}{$\begin{array}{l}\text { Frequencies } \\
\qquad(\mathrm{Hz})\end{array}$} & \multicolumn{6}{|c|}{ RCLP group } & \multicolumn{6}{|c|}{ Normal group } \\
\hline & \multicolumn{2}{|c|}{ /i/ } & \multicolumn{2}{|c|}{ /pit/ } & \multicolumn{2}{|c|}{ /tip/ } & \multicolumn{2}{|c|}{ /i/ } & \multicolumn{2}{|c|}{ /pit/ } & \multicolumn{2}{|c|}{ /tip/ } \\
\hline & $\begin{array}{l}\text { Mean } \\
\text { (dB) }\end{array}$ & SD & $\begin{array}{l}\text { Mean } \\
\text { (dB) }\end{array}$ & SD & $\begin{array}{l}\text { Mean } \\
\text { (dB) }\end{array}$ & SD & $\begin{array}{l}\text { Mean } \\
\text { (dB) }\end{array}$ & SD & $\begin{array}{l}\text { Mean } \\
\text { (dB) }\end{array}$ & SD & $\begin{array}{l}\text { Mean } \\
\text { (dB) }\end{array}$ & SD \\
\hline 396 & 33.09 & 12.01 & 42.22 & 5.95 & 44.80 & 9.82 & 29.95 & 9.43 & 41.10 & 8.33 & 42.60 & 10.67 \\
\hline 500 & 46.08 & 10.14 & 38.34 & 8.69 & 37.20 & 7.07 & 40.33 & 10.8 & 36.60 & 5.60 & 40.32 & 5.22 \\
\hline 630 & 39.70 & 9.76 & 44.35 & 8.74 & 44.49 & 4.81 & 41.67 & 6.94 & 46.32 & 6.93 & 42.11 & 7.61 \\
\hline 793 & 36.75 & 6.78 & 40.32 & 5.99 & 41.31 & 8.69 & 32.74 & 6.99 & 35.42 & 5.22 & 36.23 & 7.48 \\
\hline 1000 & 28.98 & 8.09 & 40.32 & 7.17 & 37.44 & 4.29 & 27.30 & 9.18 & 30.17 & 6.81 & 29.50 & 5.07 \\
\hline 1259 & 27.13 & 6.77 & 36.76 & 9.74 & 32.94 & 7.54 & 21.22 & 11.11 & 26.75 & 4.39 & 26.05 & 4.77 \\
\hline 1587 & 25.86 & 7.54 & 34.27 & 8.19 & 33.96 & 8.50 & 17.19 & 9.98 & 25.45 & 5.68 & 24.26 & 4.34 \\
\hline 2000 & 27.25 & 6.08 & 34.70 & 5.72 & 34.25 & 5.20 & 19.22 & 10.82 & 26.95 & 9.01 & 24.99 & 4.36 \\
\hline 2519 & 28.85 & 6.04 & 39.47 & 7.97 & 39.18 & 8.28 & 27.90 & 8.28 & 37.55 & 8.31 & 33.30 & 4.59 \\
\hline 3174 & 36.31 & 6.34 & 40.92 & 7.42 & 40.61 & 6.74 & 39.44 & 3.99 & 44 & 6.17 & 42.01 & 7.63 \\
\hline 4000 & 36.68 & 5.66 & 40.59 & 7.53 & 40.15 & 7.43 & 39.55 & 4.05 & 39.50 & 6.59 & 39.07 & 6.70 \\
\hline 5039 & 33.36 & 6.61 & 35.33 & 9.21 & 34.58 & 7.40 & 32.50 & 5.27 & 32.54 & 7.25 & 34.35 & 6.55 \\
\hline 6349 & 26.59 & 9.64 & 27.55 & 8.16 & 25.75 & 9.59 & 22.05 & 7.56 & 23.90 & 8.22 & 26.85 & 8.01 \\
\hline 8000 & 23.99 & 5.75 & 22.86 & 7.18 & 24.15 & 6.00 & 20.05 & 8.67 & 15.94 & 4.64 & 19.71 & 4.93 \\
\hline
\end{tabular}

Table 3: Mann-Whitney $U$ test results describing frequencies showing significant differences.

\begin{tabular}{|c|c|c|c|c|}
\hline \multirow{2}{*}{ Stimuli } & Frequencies & M-W 'U' & Z value & Significance \\
\hline & $99 \mathrm{~Hz}$ & 36 & -2.09 & 0.038 \\
/i/ & $125 \mathrm{~Hz}$ & 37 & -2.02 & 0.043 \\
& $157.5 \mathrm{~Hz}$ & 29.5 & -2.45 & 0.014 \\
& $1259 \mathrm{~Hz}$ & 27 & -2.6 & 0.009 \\
& $1587 \mathrm{~Hz}$ & 27 & -2.59 & 0.009 \\
& $2000 \mathrm{~Hz}$ & 25 & -2.71 & 0.007 \\
\hline
\end{tabular}




\section{Global Journal of Otolaryngology}

\begin{tabular}{|c|c|c|c|c|}
\hline & $793.7 \mathrm{~Hz}$ & 38 & -1.96 & 0.050 \\
/pit/ & $1000 \mathrm{~Hz}$ & -2.59 & 0.009 \\
& $1259 \mathrm{~Hz}$ & 27 & -2.71 & 0.007 \\
& $1587 \mathrm{~Hz}$ & 25 & -2.59 & 0.009 \\
& $8000 \mathrm{~Hz}$ & 34.5 & -3.26 & 0.030 \\
\hline & $1000 \mathrm{~Hz}$ & 15.5 & -2.39 & 0.001 \\
& $1259 \mathrm{~Hz}$ & 30.5 & -2.83 & 0.017 \\
& $1587 \mathrm{~Hz}$ & 23 & -2.19 & 0.005 \\
& $2519 \mathrm{~Hz}$ & 34 & -2.07 & 0.028 \\
& $8000 \mathrm{~Hz}$ & 36 & & 0.038 \\
\hline
\end{tabular}

In the present study, overall the energy concentration over the one third octave spectrum for stimulus /i/, /pit/, \& /tip/ were more in RCLP group as compared to TDC group. From table 3, it can be interpreted that one-third octave spectral amplitudes at frequencies $1259 \mathrm{~Hz}, 1587 \mathrm{~Hz}$ and $2000 \mathrm{~Hz}$ showed a significant difference between normal and RCLP groups in all the three stimuli (/i/, / pit/ \& /tip/). It shows that irrespective of the context, these mid frequencies were sensitive enough to discriminate the two groups. For isolated vowel /i/, significant differences in spectral energies between RCLP and control group was found at lower frequencies $(97 \mathrm{~Hz}, 125 \mathrm{~Hz}$, and $157.5 \mathrm{~Hz})$. However, the significant difference in spectral energies was not found for the same frequencies for vowel /i/ in the presence of a context (pit, tip). For /pit/, frequencies such as $793.7 \mathrm{~Hz}, 1000 \mathrm{~Hz}, 1259 \mathrm{~Hz}, 1587 \mathrm{~Hz}$ and $8000 \mathrm{~Hz}$ differentiated the normal from RCLP group. The significant difference was exhibited at frequencies $1000 \mathrm{~Hz}, 1259 \mathrm{~Hz}, 2519 \mathrm{~Hz}, 1587 \mathrm{~Hz}$ and $8000 \mathrm{~Hz}$ for the stimulus /tip/.

\section{Discussion}

The present study aimed to find out the differences in spectral amplitudes between children with RCLP and typically developing children (TDC) across stimuli. One of the major findings of the study is that the energy concentration over the one third octave spectrum was found to be more in RCLP group for across the stimulus compared to TDC group. This result is in consensus with the findings of a previous study conducted by Navya et al. $[13,14]$ who reported higher spectral amplitudes at all the one-third octave spectral frequencies for the vowel /a/ and /i/ in RCLP than in normals. The result was also supported by Kataoka et al., [10] who also found increased amplitudes for the hypernasal group of isolated vowels compared to control group. The possible explanation for increased spectral energy in the vowel production of children with RCLP is due to the presence of reinforced harmonics at frequencies where the energy is not normally expected. However, the contradictory findings were found in majority of the studies who have reported reduction in the amplitude of all formants in hypernasal speech $[4,14,11]$

The second major finding of the study is that the isolated vowel /i/ had shown significant differences in spectral energies between RCLP and control group at lower frequencies $(97 \mathrm{~Hz}$, $125 \mathrm{~Hz}$, and $157.5 \mathrm{~Hz}$ ). The present result can also be explained by the earlier findings of the study carried out by Navya [14]. In their study, they reported that for vowel /i/ the amplitudes below $1 \mathrm{kHz}$ showed increased values and were sensitive in differentiating the two groups. This is explained as there was the potential effect of the introduction of pole-zero pairs in the transfer function due to the coupling of the nasal tract to the main vocal tract. When the high vowel /i/ becomes nasalized, the pole-zero pair emerges in the high-frequency region. As a result, the amplitude of F1 is not attenuated. Glass and Zue [15] also repoted noticeable differences in the magnitude of spectrum between the nasalized and nonnasalized vowels in the low-frequency regions which highlight the importance of low frequencies in differentiating control group from hypernasality group.

Another finding of the current study is that, the spectral amplitude of vowel /i/ in the context of / pit/ and /tip/ differentiated the normal from RCLP group at $793.7 \mathrm{~Hz}, 1000 \mathrm{~Hz}, 1259 \mathrm{~Hz}, 2519 \mathrm{~Hz}$ and $8000 \mathrm{~Hz}$ by exhibiting increased amplitudes for RCLP group Similar results were obtained by Lee, Ciocca, \& Whitehill [16] who also used non nasal words in consonant-vowel-consonant (CVC) combinations (e.g., /pit/, /tip/) and found that participants with hypernasal speech tended to have higher intensity levels at bands centered at $630 \mathrm{~Hz}, 800 \mathrm{~Hz}$, and $1000 \mathrm{~Hz}$, as well as lower intensity levels for the band centered at $2.5 \mathrm{KHz}$ compared to speakers with normal resonance. However, the justification for the findings obtained and explanation about the contextual effect was not provided by the authors in their work.

The study also reported higher amplitudes for /pit/ and / tip/ across frequencies compared to the isolated vowel /i/, for both the groups of RCLP and TDC. This finding can be correlated well with coarticulatory studies [13,11,17-22]. These studies focused on consonantal context effect on spectral and temporal characteristics of vowels and have shown that the vowels undergo phonetic reduction owing to the influence of consonantal context. The phonetic reduction of a vowel entails a reduction in the acoustic duration of the vowel and formant undershoots (i.e, a change in formant frequencies from their ideal target values). As a result, it can be decoded that these potential spectral modifications in a vowel due to the effect of phonetic context might alter the amplitude related information and frequency specific differences can be described on the same basis. Thus the study concluded that coarticulation results in higher spectral amplitudes in vowel /i/ in the context of /pit/ and /tip/ compared to isolated vowel /i/ and were attributed to the phonetic reduction of vowel /i/. Overall, the RCLP group exhibited higher one third octave spectral amplitudes than control group. 


\section{References}

1. Kent R, Read C (2002) Acoustic Analysis of Speech, $2^{\text {nd }}$ edn (San Diego, California: Singular, Thomas Learning).

2. Kim RD, Kim YJ (2003) Toward an acoustic typology of motor speech disorders. Clinical linguistics \& phonetics 17(6): 427-445.

3. Kent RD, Liss J, Philips BJ (1989) Acoustic analysis of velopharyngeal dysfunction in speech. In K R Bzoch (Eds.) Communicative disorders related to cleft lip and palate. Boston Little Brown, Bostan, US, pp. 258270.

4. Chen, Marilyn Y (1996) Acoustic correlates of nasality in speech (Doctoral dissertation, Massachusetts Institute of Technology).

5. Kataoka R, Michi K, Okabe K, Miura T, Yoshida H (1996) Spectral Properties and Quantitative Evaluation of Hypernasality in Vowels. The Cleft Palate-Craniofacial Journal 33(1): 43-50.

6. Navya A, Pushpavathi M (2013) One third octave analysis: a diagnostic tool to measure nasality in conjunction with nasalance in children with repaired cleft lip and palate. Journal of the All India Institute of Speech \& Hearing 32: 36-44.

7. Navya A (2015) Construction of nasality severity index (Unpublished master's thesis). University of Mysore, Mysore, India.

8. Kent RD, Weismer G, Kent JF, Vorperian HK, Duffy JR (1999) Acoustic studies of dysarthric speech: Methods, progress, and potential. Journal of communication disorders 32(3): 141-189.

9. Watterson T, Emanuel F (1981) Observed effects of velopharyngeal orifice size on vowel identification and vowel nasality. The Cleft palate journal 18(4): 271-278.

10. Hajek J, Maeda S (2000) Vowel height and duration on the development of distinctive nasalization. Papers in Laboratory Phonology V: Acquisition and the lexicon 52-69.

11. House A, Stevens KN (1956) Analog studies of the nasalization of vowels. Journal of Speech and Hearing Disorders 21(2): 218-232.
12. Moll KL (1964) Objective measures of nasality. The Cleft palate journal 35: 371-374.

13. Lindblom B (1963) Spectrographic study of vowel reduction. The journal of the Acoustical society of America 35(11): 1773-1781.

14. Hattori S, Yamamoto K, Fujimura O (1958) Nasalization of vowels in relation to nasals. The Journal of the Acoustical Society of America 30(4): 267-274.

15. Glass J, Zue V (1985) Detection of nasalized vowels in American English. In Acoustics, Speech, and Signal Processing, IEEE International Conference on ICASSP'85 10: 1569-1572.

16. Lee ASY, Ciocca V, Whitehill TL (2003) Acoustic correlates of hypernasality. Clinical Linguistics \& Phonetics 17(4-5): 259-264.

17. Strange W, Verbrugge RR, Shankweiler DP, Edman TR (1976) Consonant environment specifies vowel identity. The Journal of the Acoustical Society of America 60(1): 213-224.

18. Schouten MEH, Pols LC (1979) Vowel segments in consonantal contexts: a spectral study of coarticulation. Part I Journal of Phonetics 7: 1-23

19. Andruski JE, Nearey TM (1992) On the sufficiency of compound target specification of isolated vowels and vowels in/bVb/syllables. The Journal of the Acoustical Society of America 91(1): 390-410.

20. Strange W, Bohn OS (1998) Dynamic specification of coarticulated German vowels: Perceptual and acoustical studies. The Journal of the Acoustical Society of America 104(1): 488-504.

21. Hillenbrand JM, Clark MJ, Nearey TM (2001) Effects of consonant environment on vowel formant patterns. The Journal of the Acoustical Society of America 109(2): 748-763.

22. Ohde RN, Sharf DJ (1998) Coarticulatory effects of voiced stops on the reduction of acoustic vowel targets. The Journal of the Acoustical Society of America 58(4): 923-927.

\section{Your next submission with Juniper Publishers will reach you the below assets}

- Quality Editorial service

- Swift Peer Review

- Reprints availability

- E-prints Service

- Manuscript Podcast for convenient understanding

- Global attainment for your research

- Manuscript accessibility in different formats ( Pdf, E-pub, Full Text, Audio)

- Unceasing customer service

Track the below URL for one-step submission https://juniperpublishers.com/online-submission.php 